\title{
The "New" Carbon Economy: What's New?
}

\section{Emily Boyd}

School of Earth and Environment and Sustainability Research Institute,

University of Leeds, Leeds, UK;

e.boyd@leeds.ac.uk

\section{Maxwell Boykoff}

Center for Science and Technology Policy Research, University of Colorado, Boulder, CO, USA;

boykoff@colorado.edu

\section{Peter Newell}

School of International Development, University of East Anglia Norwich, UK;

p.newell@uea.ac.uk

\section{Introduction}

We now have what is commonly called a carbon economy. However, it is in fact made up of several, increasingly inter-connected, carbon markets. It takes different forms in different parts of the world, but includes systems of emissions trading (in the EU, some states in the USA and emerging schemes in cities, such as Montreal), and the buying and selling of offsets through United Nations-controlled "compliance" markets, most notably though the Clean Development Mechanism (CDM) created by the Kyoto Protocol, as well as through "voluntary" markets. The carbon economy has had a turbulent history: its monetary value was affected by global financial meltdown, which also suppressed levels of demand for carbon credits, and its legitimacy questioned amid claims of climate fraud, "toxic carbon", and acts of (neo)colonial dispossession (Bachram 2004; Friends of the Earth 2009; Lohmann 2005, 2006).

And yet the importance of the carbon economy should not be underestimated. With the CDM, for example, Certified Emissions Reductions (CERs) amounting to more than 2.7 billion tonnes of carbon dioxide equivalent are expected to be produced in the first commitment Antipode Vol. 00 No. 002011 ISSN 0066-4812, pp 1-11 doi: $10.1111 / \mathrm{j} .1467-8330.2011 .00882 . \mathrm{x}$ 
period of the Kyoto Protocol (2008-2012) (United Nations Framework Convention on Climate Change-UNFCCC 2010). The revenues of the CDM constitute the largest source of mitigation finance to developing countries to date (World Bank 2010). Over the 2001-2012 period, CDM projects could raise US\$15-24 billion in direct carbon revenues for developing countries. Actual revenues will, of course, depend on the price of carbon. The voluntary carbon market, meanwhile, saw early exponential growth with a tripling of transactions between 2006 and 2007 , when it was worth US $\$ 331$ million. It remains only fraction of the size of regulated markets though, and had its value nearly halve in 2009 to US\$387 million and fall by a quarter in volumes of carbon transacted (Capoor and Ambrosi 2009). These markets remain important but very unstable. What is perhaps most notable is that, despite these crises, faith in carbon markets as a key element of global responses to the threat of climate change remains strong, as affirmed by the recent UN climate change meeting in December 2010 in Cancún.

The world of climate politics was not always thus. In the years up to 1992, being built on foundations similar to those of other multilateral environmental agreements, and particularly coming in the wake of the apparently successful ozone regime, a command and control process of setting targets globally that countries enforce nationally seemed a logical way to proceed for the climate regime. This after all was the template for numerous previous regimes aimed at regulating pollutants of one form or another. Yet, even as discussions moved from the UNFCCC to efforts to produce a legally binding emissions reductions treaty, opposition set in. This was not an issue amenable to convenient technofixes such as the substitution of damaging chemicals (replacing CFCs with HCFCs as in the case of ozone) or one that only affected a handful of large multinational enterprises in the core of the global economy for whom alternative accumulation strategies could easily be identified. The ramifications of regulating energy supply and use to the world's economy, upon which growth depends, made climate change a "wicked" policy challenge.

It soon became clear that if action were to be taken at all, and particularly by those economies contributing most to the problem, markets offered the most politically acceptable solution as part of a suite of measures to bring down the costs associated with reducing emissions and increase flexibility about where emissions' reductions take place. Market-based solutions aligned closely with prevailing ideologies regarding regulation and the primacy of "efficiency" and the preferences of powerful fractions of capital in leading economies for trading schemes over taxes or regulation. Their incorporation became the quid pro quo for the involvement of the USA in particular (notwithstanding the fact that having insisted on flexible mechanisms, the USA then walked away from the Kyoto deal). The USA fought 
hard to project the "success" of its sulphur dioxide trading scheme as a model for carbon trading, while domestic industries sought to avoid domestic reduction measures that might drive capital overseas and had a clear preference for paying others to reduce where it is cheapest to do so (Gilbertson and Reyes 2009). The prospect of transfer of resources from the global North to South through trading of offsets also provided an incentive for many developing countries' governments to support market-based approaches. Emissions trading and the CDM were what eventually resulted from this confluence of potential beneficiaries from the carbon economy.

Businesses, meanwhile, came under pressure to demonstrate their contributions to tackling climate change. After many years of hostile opposition to action (Newell and Paterson 1998), some began to see a business case for action on climate change aimed at meeting demand for lower carbon products and services as well as providing carbon offset projects for clients and consumers wanting to claim "carbon neutrality". Voluntary carbon offsets met this need.

Told this way, it would appear that the "new" carbon economy is a relatively novel phenomenon, though offset providers will remind you that the first carbon offset project was as far back as 1989. Many claims to novelty are made about the "new" carbon economy nevertheless, not least by the actors and beneficiaries of the economy themselves who seek to identify new opportunities in the reduction of carbon and technological innovation. It is also the case that the political, scalar and temporal challenges of climate change are often deemed to be novel and unprecedented (Giddens 2009). To some, the "new" carbon economy is seen as capable of overcoming resistance to action on climate change by generating new sites of accumulation or by linking "local" and "global" spaces of climate governance, through offsets, for example.

What we have briefly described above is illustrative of an important transition that has taken place in the nature of responses to climate change that reflects and advances a particular form of neo-liberalism. The carbon economy may be novel then in the sense that it would not have been politically viable or imaginable even 20 years earlier, and because it bears the hallmarks of a specific period of capitalist development in terms of the confluence of forces in engages (finance capital in particular) and the characteristics it displays (reliance on networks, globalised market opportunities) (Newell and Paterson 2009). While there are certainly precedents for the creation of markets to address resource overconsumption (around fisheries and in the area of conservation for example), in terms of its reach and scale (geographically and sectorally), the range of powerful actors now engaged and the levels of finance being circulated in the carbon economy, claims of newness go beyond describing the banal existence of a newly created market and describe instead the emergence of 
an historically unparalleled experiment in marketised environmental governance. Many of the politics and actors which created and sustain the carbon economy and the political and social challenges they create, may be less novel, however. So what is really new about the "new" carbon economy?

There remains a clear need for researchers to subject claims of newness and uniqueness to critical scrutiny. By this we refer to the need to historicise such claims, identify precedents, explore them comparatively and reveal embedded assumptions and politics. This is the purpose of this special issue. We suggest three areas in particular where claims of novelty arise and which require further attention: the ecological and social inputs which produce, sustain and constitute the new carbon economy; the governance issues and challenges that arise from the commodification and trading of carbon; and the effects it generates: the winners and losers from this economy. We can summarise this trio as novelty in the constitution, governance and effects of the new carbon economy.

\section{Constituting the "New" Carbon Economy}

Many of the essays in this special issue focus on the materiality of carbon (such as that by Bumpus): its physical properties and how this affects its enrolment into the global circuits of capital. Whether emphasising its "uncooperative nature" (Bakker 2004), how difficult it is to measure or to control in ways that commodification demands, or the failed articulations between global capital and local socio-ecological systems that Lansing explores, many contributions highlight the need to take seriously the biophysical properties of carbon. These properties may give rise to new governance challenges (in terms of commodification, measurement and exchange) or produce distinct forms of socio-ecological relations. So what's the "matter" with carbon?

Focusing on carbon can be seen as somewhat reductionist: there are greenhouse gases that do not contain carbon (e.g. nitrous oxide), and not all carbon-containing emissions (e.g. carbon monoxide) trap heat. However, markets in greenhouse gas reductions are organised around carbon dioxide equivalence to create "exchange value" and a fungible commodity that can be traded across products and projects. As Gavin Bridge has noted, carbon has become:

a common denominator for thinking about the organization of social life in relation to the environment ... from fossil-fuel addiction and peak oil to blood barrels and climate change, carbon's emergence as a dominant optic for thinking and writing about the world and human relations within it is tied to the various emergencies with which it is associated (Bridge 2010:2). 
Carbon is literally embedded in different territories, histories, economies and politics of which climate change is merely a latest addition. It is part of a cycle involving forests and oceans: it moves and is not static, part of what Lansing refers to in this issue as the "precarious choreography of the global carbon cycle". These properties matter. This leads to framing and boundary contests over, for example, what count as forests (Gutiérrez, this issue), the extent to which forests hold carbon, for how long and on whose behalf and how responses to climate change physically and politically reconfigure landscapes (Phadke, this issue). Decisions to preserve carbon stocks in forests and land, or to keep it in the ground, imply huge social and economic trade-offs for those whose livelihoods depend on carbon in fossil fuels. Moreover, a great deal of work-politically and literally in the form of labour-goes into producing, extracting value from, and commodifying, materials which contain carbon, as well products which claim to prevent the release of carbon; offsets that can be bought and sold. Attempts to regulate carbon often pitch industries such as coal alongside trade unions, such as those representing mineworkers, against environmentalists calling for limits on use. Workers may be well aware that their labour produces surplus value for their employees from which they are excluded, but the fate of the industry represents their own fate. These histories, conflicts and social dynamics form the basis of the forms of governance that have been created to manage the carbon economy and to keep carbon capital in circulation.

\section{Governing the "New" Carbon Economy}

Many claims of newness in relation to the new carbon economy relate to its governance dimensions. Critics focus on its lack of governance, its unregulated and "wild west" nature. This is considered particularly problematic when the system is premised on claims of additionality: having to prove that emissions reductions would not have been achieved without the offset. Others, such as the World Bank, talk of a "flight to quality" as offset providers in voluntary carbon markets increasingly emulate the use of governance and quality assurance tools in compliance markets such as project design documents, third party verification and use of voluntary standards. Reviews of carbon markets observe:

Over the past 2 years numerous writers and analysts have likened the voluntary carbon markets to the "wild west". In 2007 market trends highlight that this frontier has become a settlement zone. Customers are increasingly savvy about the opportunities and pitfalls in the carbon offset domain and stakeholders are aggressively working to forge the rules of the game and structures to enable smooth transactions (Hamilton et al 2008:53). 
As much as $50 \%$ of the transactions conducted in 2007 involved credits verified to a specific third party standard. This is clearly a rapidly evolving market.

From being sold as a response to climate change that implied lower transaction costs, it was perhaps inevitable that, as with all markets, property rights and rules are required to bring them into being and ensure their smooth functioning. As Polyani (1944) showed, laissezfaire approaches to markets often produce demands to re-embed markets in frameworks of social control. Even key participants in carbon markets acknowledge the inevitability of this. Abyd Karmali, Managing Director, Global Head of Carbon Markets, Merrill Lynch reflects that:

Those who assume that the carbon market is purely a private market miss the point that the entire market is a creation of government policy. Moreover, it is important to realize that, to flourish, carbon markets need a strong regulator and approach to governance. This means, for example, that the emission reduction targets must be ratcheted down over time, rules about eligibility of carbon credits must be clear etc. Also, carbon markets need to work in concert with other policies and measures since not even the most ardent market proponents are under any illusion that markets will solve the problem (ClimateChangeCorp 2009).

But beyond the issue of the rules and regulations which should underpin the functioning of carbon markets, other contributors to this special issue focus on the scalar politics of the new carbon economy and the specific governance challenges it generates (eg see Boyd 2009). Bailey et al explore the politics of scale in relation to the EU Emissions Trading Scheme (ETS) and its connections to the more "global" offset market. It is certainly the case that we find interesting - possibly unprecedentedcombinations of public, private and hybrid governance encountering one another and having to work together to enable the new carbon economy to function. Bailey et al show this in relation to the CDM with the armies of auditors, project developers, regulators, lawyers and accountants that have to be mobilised to bring a project into being and see it through the labyrinthine processes of accreditation and verification. It is perhaps the combination of these forms of governance across scales, as well as the governance deficits this often leaves, that create a "wicked" challenge in relation to the new carbon economy.

The response to the question of newness when posed in relation to governance might focus on the plurality of governance forms or modes, the multiple levels at which it operates and the process challenges that are intensified when an attempt is made to govern globally (as with the CDM Executive Board) local resource use decisions around forests, waste and energy, imbued as they are in conflicting systems of value and property rights in diverse settings. This comes through 
clearly in David Lansing's essay which shows what happens when the logics of global capital and local socio-ecological systems meet through the new carbon economy. The potential for negative social and environmental consequences is a function of the "articulation between the abstract representations required of commodification and the socioecological complexity of locally produced natures". Again, fair trade or other supply chains in commodities like seeds, timber or coffee require elaborate systems of tracing and tracking, attempts to monitor local conditions by global actors (buyers and multinational companies) and enroll "local" resources in "global exchange". Perhaps what is unique in relation to the compliance carbon markets is the UN's role as an arbiter of quality control and the public good feature which attempts to commodify carbon must also demonstrate.

Another interesting theme in this special issue is not just how the new carbon economy creates particular governance challenges and requires specific forms and practices of governance in order to work, but how distinct governance systems intended for other purposes are incorporated into the new carbon economy and have to be re-worked to ensure they can operate in the service of carbon trading. These include the activities of credit-rating agencies, the creation of insurance products (on volumes of CERs likely to be delivered for example), (weather) derivatives, systems of disclosure (such as the Carbon Disclosure Project): what Descheneau and Paterson (this issue) refer to as the "routinization" of financial products in carbon markets. In this way, "carbon market actors borrow from existing financial practices to make the emerging market readily intelligible, to enable it to operate as a matter of financial routine". Interestingly their essay also highlights the importance of "desire" whereby what is being sold is "not the tonne per se but rather the financial or discursive representations of it".

Claims of newness might also focus on the technologies of governance or governmentalities that have to be employed to make the new carbon economy work through elaborate systems of auditing, measurement and accounting, as Lovell and MacKenzie show so vividly (this issue). Put more critically, Prudham, echoing Lansing's claims, suggests these practices "render the messy materiality of life legible as discrete entities, individuated and abstracted from the complex social and ecological integuments" (Prudham 2007:414). Again, the problem of commensurability is not unique to carbon markets. Money-based economies require us to place "comparable" values on products as diverse as water, coffee and bananas, for example. The price paid does not accurately reflect the labour value or environmental costs invested in their production and it requires an act of faith on the part of consumers to value them through the medium of money and price determined by supply and demand. This draws our attention again to the point Descheneau and Paterson make about the importance of the rituals 
and imagery that is used to create "romance" around the new carbon economy and the products and services it seeks to sell in the production of desire. Brand and image management are crucial to packaging a particular carbon product to a client wanting to gain public relations value from it.

\section{Effects of the "New" Carbon Economy}

It is perhaps as a result of both the material(ity) of carbon, its value and omnipresence, that underpins claims about the "nature" of the new carbon economy, and the forms of governance produced by and demanded of the new carbon economy, that create in their wake a series of social, environmental and political effects. This gives rise to a third set of claims about novelty which the essays in this special issue touch upon.

There are claims of the uneven development that results from the ways in which carbon is commodified or offsets produced in the essays by Bumpus and Gutierrez. Again, claims about the uneven (and combined) nature of development in a capitalist context have a very long history. In the context of the new carbon economy such claims refer to the inequalities in consumption and resource access which underpin carbon markets by making it more cost-effective and lucrative to pay for emissions reductions in poorer parts of the world. Gutierrez highlights the role of time and risk in particular in reproducing uneven development. Such claims also refer to the additional value which resources such as forests or municipal waste can attract as a result of carbon markets-forests because they absorb carbon, waste because methane can be captured and burned and a vast number of carbon dioxide equivalent credits acquired. Those living in forests or alongside waste dumps find their livelihoods and life chances disrupted by the value these resources acquire, which means forest conservation for carbon sequestration may trump sustainable use and keeping a waste site open trumps campaigns to close it because of the finance secured through carbon markets.

Perhaps it could be argued that all interventions in the form of aid or investment have the potential to reinforce existing inequalities and change the value and viability of existing livelihood options, not just carbon markets. Carbon markets may be unique in their scope in that gases that are not carbon but which contribute to climate change, and which emanate from a vast array of human activities, are made equivalent. This opens up nearly all sectors of the economy in all parts of the world to the potential reach of carbon markets. The anonymity of the exchange and the distance between buyer and seller in carbon markets may be greater than in direct negotiations with donors or investors, a fact again which heightens both the importance of effective mediating 
institutions and the work of imagery and narrative in constructing convincing stories which connect abstract commodities to particular places.

Beyond the material and economic consequences of the carbon economy, we also observe in the essay by Bailey et al the political consequences of the preference to address climate change by producing markets in carbon. These authors explore the ways in which notions of ecological modernisation are invoked to rationalise and justify the enhanced marketisation of environmental governance to the exclusion of adequate consideration of other policy alternatives. Equally viable options in technological or even economic terms get screened in or out of policy debate because of their political acceptability. Phadke's essay on "big wind" in the USA also shows us, however, that policy responses considered to be important and effective in efforts to address climate change, such as the promotion of renewable energy, also provoke acts of resistance when handled poorly.

\section{Conclusions}

The essays in this special issue raise a number of challenges for political engagement with the new carbon economy and for academic attempts to make adequate sense of it.

Firstly, there are a set of strategic issues about whether and on what terms to engage with the new carbon economy through efforts to improve its governance, to find spaces to promote alternative policy options or to resist the further development of the new carbon economy. We have seen above how the nature and organisation of the new carbon economy raises a series of issues of equity and (social and environmental) justice about who gains and who bears the costs of responding to climate change in this way. Critics argue that the pursuit of carbon markets as the preferred option has lost us more than 10 years in the battle to keep climate change within tolerable levels. The time required to create them, manage them and deal with the problems they inevitably raise (additionality, fungibility) has meant that 10 years on we have poorly performing carbon markets (from the point of view of seriously reducing emissions) and other alternatives that could have been more effective have been successfully sidelined.

As the essay in this issue by Bailey et al shows, discourses of ecological modernisation and eco-efficiency provide legitimation to claims that markets can be an essential component of responses to climate change while underplaying some of the contradictions and tensions that relying on them implies. And yet we are left with the dilemma of capitalism of one form or another providing the near-term context in which we have to respond to climate change. Mobilising the influence of powerful fractions of capital means identifying 
viable accumulation strategies that are compatible with the goal of de-carbonisation. Pricing and carbon trading mechanisms are, in the end, just one small component of a much broader transformation that is required in capitalism if the worst effects of climate change are to be averted (Newell and Paterson 2010).

Secondly, at a theoretical level we have seen how concepts and tools drawn from Marxism, post-structuralism, cultural political economy and actor network theory generate insights into specific features and aspects of the new carbon economy. Future work might explore fruitful and productive combinations of these approaches that will produce the sort of multi-faceted and multi-dimensional explanations we need of how the new carbon economy functions and for whom, paying attention all the while to the broader social, economic and ecological relations of which it is part and which, if it is to be successful, it has to transform.

Each of the perspectives utilised in the essays here produces a different angle on what might or might not be novel about the new carbon economy. Are we witnessing a routine attempt by the social forces of capital to render the challenge of climate change non-threatening to, and even profitable for, its accumulation objectives, or is there evidence of deeper processes of transformation at work? What limits are suggested by the nature of carbon itself or the technologies of governance it requires to be pressed into the service of international responses to climate change or accumulation strategies? How do people resist, engage with and imagine the new carbon economy? These are just some of the questions the essays here pose, but our aim is ultimately to provoke further debate and reflection about the new carbon economy and what challenges it poses for activists and scholars alike.

\section{Acknowledgements}

We are grateful to Professor Diana Liverman for her support in hosting the workshop at Oxford University, which forms the basis of this special issue. We would also like to thank the participants at that event and at the panel organised on this theme at the 2009 Association of American Geographers in Las Vegas, Nevada for their time and insightful contributions and the editors of Antipode for their comments, suggestions and guidance.

\section{References}

Bachram H (2004) Climate fraud and carbon colonialism: The new trade in greenhouse gases. Capitalism, Nature, Socialism 15(4):10-12

Bakker K (2004) An Uncooperative Commodity: Privatizing Water in England and Wales. Oxford: Oxford University Press

Boyd E (2009) Governing the Clean Development Mechanism: Global rhetoric versus local realities in carbon sequestration projects. Environment and Planning A 41(10):2380-2395 
Bridge G (2010) Resource geographies I: Making carbon economies, old and new. Progress in Human Geography DOI: 10.1177/0309132510385524

Capoor K and Ambrosi P (2008) State and Trends of the Carbon Market 2008. Washington DC: World Bank

Capoor K and Ambrosi P (2009) State and Trends of the Carbon Market 2009. Washington DC: World Bank

ClimateChangeCorp (2009) Is carbon trading the most cost-effective way to reduce emissions? http://www.climatechangecorp.com/content.asp?ContentID=6064 (last accessed 2 April 2009)

Friends of the Earth (2009) Sub-Prime Carbon: Re-thinking the World's Largest New Derivatives Market. Washington DC: Friends of the Earth

Giddens A (2009) The Politics of Climate Change. Cambridge: Polity

Gilbertson T and Reyes O (2009) Carbon trading: How it works and why it fails. Critical Currents 7 http://www.carbontradewatch.org/articles/new-book-exposes-dangers-ofcarbon-market-ahead-of-bolivia-climates.html (last accessed 21 July 2010)

Hamilton K, Sjardin M, Marcello T and Xu G (2008) Forging a Frontier: State of the Voluntary Carbon Markets 2008. Washington, DC: Ecosystem Marketplace and New Carbon Finance

Lohmann L (2005) Marketing and making carbon dumps: Commodification, calculation and counter-factuals in climate change mitigation. Science as Culture 14(3):203-235

Lohmann L (2006) Carbon Trading: A Critical Conversation on Climate Change, Privatisation and Power (Development Dialogue 48). Uppsala: Dag Hammarskjöld Foundation

Newell P and Paterson M (1998) Climate for business: Global warming, the state and capital. Review of International Political Economy 5(4):679-704

Newell P and Paterson M (2009) The politics of the carbon economy. In M Boykoff (ed) The Politics of Climate Change: A Survey (pp 80-99). London: Routledge

Newell P and Paterson M (2010) Climate Capitalism: Global Warming and the Transformation of the Global Economy. Cambridge: Cambridge University Press

Polyani K (1944) The Great Transformation: The Political and Economic Origins of our Time. Boston: Beacon

Prudham S (2007) The fictions of autonomous invention: Accumulation by dispossession, commodification, and life patents in Canada. Antipode 39(3):406-429

UNFCCC (2010) CDM http://cdm.unfccc.int/Statistics/index.html (last accessed 13 December 2010)

World Bank (2010) Development and Climate Change (World Development Report). Washington DC: World Bank 